Article

\title{
Bioactivity-Guided Isolation of Antimicrobial and Antioxidant Metabolites from the Mushroom Tapinella atrotomentosa
}

\author{
Zoltán Béni ${ }^{1}$, Miklós Dékány ${ }^{1}$, Bernadett Kovács ${ }^{2}$, Boglárka Csupor-Löffler ${ }^{2}$, \\ Zoltán Péter Zomborszki ${ }^{2}$, Erika Kerekes ${ }^{3}$, András Szekeres ${ }^{3}$, Edit Urbán ${ }^{4}$, \\ Judit Hohmann ${ }^{2,5, *}$ and Attila Ványolós ${ }^{2, *}$ \\ 1 Spectroscopic Research, Gedeon Richter Plc., Gyömrői út 19-21, H-1103 Budapest, Hungary; \\ z.beni@richter.hu (Z.B.); M.Dekany@richter.hu (M.D.) \\ 2 Department of Pharmacognosy, University of Szeged, Eötvös u. 6, H-6720 Szeged, Hungary; \\ kovacs.bernadett@pharmacognosy.hu (B.K.); csupor.boglarka@pharmacognosy.hu (B.C.-L.); \\ zombozope@pharmacognosy.hu (Z.P.Z.) \\ 3 Department of Microbiology, University of Szeged, Közép fasor 52, H-6726 Szeged, Hungary; \\ kerekeserika88@gmail.com (E.K.); andras.j.szekeres@gmail.com (A.S.) \\ 4 Institute of Clinical Microbiology, University of Szeged, Semmelweis u. 6, H- 6725 Szeged Hungary; \\ urban.edit@med.u-szeged.hu \\ 5 Interdisciplinary Centre for Natural Products, University of Szeged, Eötvös u. 6, H-6720 Szeged, Hungary \\ * Correspondence: hohmann@pharm.u-szeged.hu (J.H.); vanyolosa@pharmacognosy.hu (A.V.); \\ Tel.: +36-62-54-6455 (A.V.)
}

Received: 10 April 2018; Accepted: 27 April 2018; Published: 4 May 2018

\begin{abstract}
Bioassay-guided fractionation of the chloroform extract of Tapinella atrotomentosa led to the isolation of four secondary metabolites 1-4. Two of the compounds are lactones-osmundalactone (1) and 5-hydroxy-hex-2-en-4-olide (2)—while 3 and 4 were identified as terphenyl quinones, spiromentins $\mathrm{C}$ and $\mathrm{B}$, respectively. The structures of the compounds were established on the basis of NMR and MS spectroscopic analysis. The isolated fungal metabolites were evaluated for their antibacterial activities against several Gram-positive and negative bacteria. In addition, their synergistic effect with cefuroxime against methicillin-resistant Staphylococcus aureus (MRSA) was also evaluated. Compounds 1-3 proved to possess significant antibacterial activity against multiresistant Acinetobacter baumannii and extended-spectrum $\beta$-lactamase (ESBL)-producing Escherichia coli. The investigation of the antioxidant effect of the isolated compounds in DPPH and ORAC assays revealed that spiromentins C (3) and B (4) have remarkable antioxidant activity.
\end{abstract}

Keywords: Tapinella atrotomentosa; terphenyl quinones; antibacterial; antioxidant; multiresistant Acinetobacter baumannii; ESBL Escherichia coli

\section{Introduction}

Fungi and primarily Basidiomycota mushrooms are recognized as valuable sources of natural products with a great structural diversity, including cyclic peptides, steroids, sesquiterpenes and polysaccharides. They are known to exhibit various beneficial pharmacological properties such as antibacterial, immunmodulatory, hypocholesterolemic and antioxidant activities with a considerable therapeutic potential [1].

In our search for higher mushrooms with antibacterial activity we previously demonstrated that several species native to Hungary exerted notable activity on Gram-positive and negative bacteria. Among these the extracts of Tapinella atrotomentosa (Batsch) Šutara revealed not only a 
broad-spectrum antimicrobial activity on Gram-positive and negative pathogens, but demonstrated also a significant inhibitory activity against resistant bacterial strains [2]. T. atrotomentosa-velvet rollrim by its vernacular name-is a wood-rotting mushroom belonging to the Tapinellaceae family. It has a global distribution, being a quite common species in Europe, Asia and North-America, occurring on the roots and stumps of dead Pinus species. Although it was once consumed in some regions of Eastern Europe, this species is now considered inedible due to its bitter taste.

Previous studies have revealed the presence of a variety of compounds in this species. Gaylord et al. identified diphenyl-substituted tetronic acid pigments from cultures of T. atrotomentosa, namely xerocomic acid and atromentic acid [3]. The species produces orange-yellow flavomentin and violet spiromentin pigments, which possess terphenylquinone structures [4]. Atromentin, the 4,4-dihydroxy analogue of polyporic acid, accounts for the reddish-brown color of the external parts of T. atrotomentosa [5]. Leucomentins, the colorless precursors of atromentin also occur in the species [6]. Further to these, the species is known to biosynthesize several lactone type compounds including osmundalactone and bis-osmundalactone $[7,8]$. Velvet rollrim belongs to the few mushroom species containing rare ergostane-type ecdysteroids (e.g., paxillosterone and atrotosterones $\mathrm{A}-\mathrm{C}$ ) [9].

Based on the promising results of our previous antimicrobial screening study T. atrotomentosa has been selected for further detailed mycochemical experiments to determine its secondary metabolites responsible for the observed antibacterial properties. The present study reports on the major outcomes of the bioactivity-guided isolation of the extract of T. atrotomentosa and the pharmacological evaluation of the isolated compounds.

\section{Results and Discussion}

In the last years bacterial resistance to first-choice antibiotics have become a major problem with global impact on human population. The association between multiresistant microorganisms and nosocomial infections places a huge burden on health care systems in many countries around the world. This critical situation is even worsened by the fact that in the past decades the antimicrobial research was a fairly neglected area. In this perspective, there is an urgent need for more intense search to develop new anti-infective agents to enter the antimicrobial therapy. The contribution of mushroom metabolites to antibacterial therapy is low, but with a large unexplored potential. Most of the studies dealing with the antimicrobial properties of higher fungi report on the activity of mushroom's extracts of different polarities without identifying the compounds responsible for the observed activity. Nevertheless some antibacterial fungal metabolites were isolated e.g., anthraquinones from Cortinarius basirubescens [10], sesquiterpenes from the edible and medicinal species of Flammulina velutipes [11], and prenylphenyl derivatives from Albatrellus flettii [12].

In the framework of our project to investigate mushrooms native to Hungary for their potential pharmacological benefits we found that extracts of T. atrotomentosa exerted a broad spectrum antimicrobial activity on several bacterial strains. Detailed mycochemical experiments were carried out to identify the major compounds with antibacterial potential. The collected mushroom material was extracted with methanol on room temperature. The crude extract was subjected to solvent-solvent partition with $n$-hexane and then chloroform. The chloroform extract was separated in multiple steps using flash chromatography on normal phase. The final purification carried out by normal phase HPLC resulted in compounds $\mathbf{1 - 4}$. The isolated metabolites were subjected to NMR and MS spectroscopic investigations. Based on the spectroscopic analysis, the structures shown in Figure 1 were proposed for compounds 1-4. These structural conclusions were further confirmed by the close similarity (small deviations in the ${ }^{1} \mathrm{H}$ - and ${ }^{13} \mathrm{C}-\mathrm{NMR}$ assignments are accounted for by the different solvents used for sample preparation) found between the collected spectroscopic data (see Supplementary Materials) and those reported in the literature for the proposed structures [13-15]. Although the absolute stereochemistry has not been determined in any cases, we assume that similar metabolic pathways led to the formation of the compounds in the fruiting bodies of T. atrotomentosa both in case 
of previous isolations and in the present study. Based on this, only the single enantiomers described in the literature are depicted in Figure 1.<smiles>C[C@H]1OC(=O)C=C[C@H]1O</smiles>

1

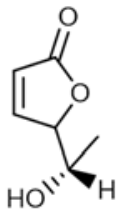

2<smiles></smiles><smiles>C[C@@H]1OC2(C=C[C@@H]1O)OC1=C(c3ccc(O)cc3)C(c3ccc(O)cc3)=C(O2)C(=O)C1=O</smiles>

Figure 1. Structures of compounds 1-4 isolated from T. atrotomentosa.

Among the isolated metabolites there are two lactone type components: osmundalactone (1) and 5-hydroxy-hex-2-en-4-olide (2), while the other two, namely spiromentin C (3) and spiromentin B (4) possess a terphenylquinone skeleton. Osmundalactone (1) was obtained for the first time from this species in 1995 by Buchanan et al. [7]. Previously this compound has been already identified both in free form and as hydrolysis product of osmundalin (a glucoside of osmundalactone) in the fern species Osmunda japonica along with 5-hydroxy-hex-2-en-4-olide (2) [13,14]. Spiromentins B and $\mathrm{C}$ were identified in T. atrotomentosa by Besl et al., and indeed this species is the single source of these pigments described so far [4]. Spiromentines belongs to the group of terphenylquinones, which represent an interesting subclass of secondary metabolites. Natural occurrence of metabolites with a $p$-terphenyl core (also known as diphenylbenzenes or triphenyls) is essentially restricted to fungi and lichens. Several $p$-terphenylquinones with unusual structural features and notable biological properties (e.g., antiproliferative, antibacterial, antioxidant, and anti-inflammatory activity) have been described in the literature [15].

Compounds 1-4 were evaluated for their antimicrobial activity against 8 bacterial strains using the microdilution method. The isolated compounds proved to possess antimicrobial properties against both Gram-positive and -negative strains (Table 1).

Table 1. Antibacterial activity of compounds 1-4 expressed in MIC values.

\begin{tabular}{ccccc}
\hline \multicolumn{5}{c}{ Calculated MIC Values $\left(\mu \mathrm{g} \mathrm{mL}^{-\mathbf{1}}\right)$} \\
\hline Compound & MACI & ESBL E. coli & Mor. catarrhalis & MRSA \\
\hline $\mathbf{1}$ & 10 & 10 & - & 250 \\
$\mathbf{2}$ & 6 & 10 & 50 & 250 \\
$\mathbf{3}$ & 20 & 10 & 50 & 250 \\
$\mathbf{4}$ & - & 100 & - & -
\end{tabular}

MACI: multiresistant Acinetobacter baumannii, ESBL E. coli: extended-spectrum $\beta$-lactamase producing Escherichia coli, Mor. catarrhalis: Moraxella catarrhalis, MRSA: methicillin-resistant Staphylococcus aureus.

Our experiments revealed that multiresistant $A$. baumannii and ESBL E. coli are the most susceptible against the studied compounds. A. baumannii and ESBL E. coli are human pathogens which have become resistant in many cases against the generally used antibacterial drugs causing serious nosocomial infections. Among the constituents 5-hydroxy-hex-2-en-4-olide (2) was the most active, although osmundalactone (1) and spiromentin C (3) have also shown significant effectiveness against these two resistant bacteria. The available data on the activity of mushroom extracts and their metabolites against $A$. baumannii are very scarce. In a study published in 2010 the activity of ethyl acetate extract of Phellinus merrillii against $A$. baumannii strains were reported to be fairly low 
with MIC values in the range of 0.71 and $1.42 \mathrm{mg} / \mathrm{mL}$ [16]. Schwan et al. screened more than 300 mushroom species native to North America for their potential activity against $A$. baumannii, but only three fungal species demonstrated more or less activity against this pathogen. Further chemical experiments identified the compound responsible for the observed antimicrobial activity, namely 2-aminoquinoline, isolated from Leucopaxillus albissimus. The MIC value of this metabolite determined for A. baumannii was $128 \mu \mathrm{g} / \mathrm{mL}$ [17]. In comparison the most effective compound in our experiments, 5-hydroxy-hex-2-en-4-olide (2) was found to have a MIC value of $6 \mu \mathrm{g} / \mathrm{mL}$ against $A$. baumannii.

In a previous study atromentin, a precursor molecule of the biosynthesis of other spiromentins, demonstrated antibacterial activity with MIC values in the range of $25-100 \mu \mathrm{g} / \mathrm{mL}$ [18]. The results of another study by Brewer et al. suggest that the antibiotic activity depends on the para substituent of the benzoquinone ring. The activity against Bacillus subtilis was found to be higher for 4,4-dimethoxyatromentin (MIC value of $5 \mu \mathrm{g} / \mathrm{mL}$ ) with respect to atromentin (MIC value of $500 \mu \mathrm{g} / \mathrm{mL}$ ) [19]. A similar tentative conclusion can be drawn for spiromentins by comparing the antimicrobial activities of the isomeric compounds, 3 and 4 . The almost complete loss of antibacterial activity parallel to the "replacement" of the furanyl with a pyranyl ring on the spiro carbon suggests that the antimicrobial activity depends on the substituents on the spiro carbon as well.

Compounds 1-4 were investigated with the aim of evaluating their synergistic effect with cefuroxime against MRSA using checkerboard techniques, though our results indicate that they do not enhance the activity of the studied antibiotic drug.

The isolated metabolites 1-4 were evaluated for their antioxidant activity using DPPH and ORAC assays. In the ORAC study spiromentins C (3) and B (4), displayed remarkable antioxidant effects $(16.21 \pm 0.38$ and $11.23 \pm 0.58 \mathrm{mmol} \mathrm{TE} / \mathrm{g}$, respectively), which were higher than the activity of ascorbic acid used as reference compound (6.97 $\pm 0.01 \mathrm{mmol} \mathrm{TE} / \mathrm{g})$ (Table 2).

Table 2. Antioxidant activity of compounds 1-4 in ORAC assay.

\begin{tabular}{cc}
\hline Compound & ORAC Antioxidant Activity $(\mathbf{m m o l ~ T E} / \mathbf{g})$ \\
\hline $\mathbf{1}$ & $0.74 \pm 0.30$ \\
$\mathbf{2}$ & $3.85 \pm 0.34$ \\
$\mathbf{3}$ & $16.21 \pm 0.38$ \\
$\mathbf{4}$ & $11.23 \pm 0.58$ \\
Ascorbic acid & $6.97 \pm 0.01$ \\
\hline
\end{tabular}

Although osmundalactone (1) and 5-hydroxy-hex-2-en-4-olide (2) were less active, they are still considered compounds with notable antioxidant property. The compounds were also tested in the DPPH assay, but either did not show any activity (compound $\mathbf{1}$ and 2 ) or could not be evaluated due to their color (purple) interference with the applied reagent at $550 \mathrm{~nm}$.

In conclusion our results demonstrates that $T$. atrotomentosa is not only a species synthesizing a great variety of secondary metabolites, but also one of the very few mushroom sources of natural compounds with significant activity against multiresistant $A$. baumannii and ESBL $E$. coli. In this vein further detailed studies are warranted to explore the potential antibacterial activity of other mushroom species to identify novel anti-infective agents effective against resistant bacterial strains.

\section{Materials and Methods}

The chemicals used in the experiments were supplied by Sigma-Aldrich Hungary (Budapest, Hungary) and Molar Chemicals (Budapest, Hungary). Flash chromatography was carried out on a CombiFlash ${ }^{\circledR} R f+$ Lumen instrument with integrated UV, UV-VIS and ELS detection using RediSep Rf Gold Normal Phase Silica Flash columns (4, 12 and 60 g) (Teledyne Isco, Lincoln, NE, USA). Normal-phase HPLC (NP-HPLC) separations were carried out on a Wufeng LC-100 Plus HPLC instrument equipped with a UV-VIS detector (Shanghai Wufeng Scientific Instruments Co., Ltd., Shanghai, China) at $254 \mathrm{~nm}$, using a Zorbax-Sil column $(250 \times 4 \mathrm{~mm}, 5 \mu \mathrm{m}$; Agilent Technologies, 
Santa Clara, CA, USA). HRMS analyses were performed on an LTQ FT Ultra system (Thermo Fisher Scientific, Bremen, Germany). The samples were dissolved in methanol. The ionization method was ESI operated in positive ion mode. The protonated molecular ion peaks were fragmented by CID. Data acquisition and analysis were accomplished with Xcalibur software version 2.0 (Thermo Fisher Scientific, Waltham, MA, USA). NMR spectra were recorded at $25{ }^{\circ} \mathrm{C}$ on a Varian 500 or $800 \mathrm{MHz}$ spectrometer Varian, Inc., Palo Alto, CA, USA) both equipped with a ${ }^{13} \mathrm{C}$ sensitivity enhanced salt tolerant ${ }^{1} \mathrm{H} /{ }^{13} \mathrm{C} /{ }^{15} \mathrm{~N}$ cryogenically cooled probe head. Samples were dissolved in deuterated chlorofom or methanol- $d_{4}$ (Eurisotop, Saint-Aubin Cedex, France). Standard one and two dimensional pulse sequences, available in the VNMJ 3.2 library were used in all cases. Chemical shifts are reported in the delta scale using TMS $\left({ }^{1} \mathrm{H}\right.$ in the case of $\left.\mathrm{CDCl}_{3}\right)$, residual solvent signal $(3.31 / 49.15$ ppm for ${ }^{1} \mathrm{H} /{ }^{13} \mathrm{C}$ in the case of MeOD- $d 4$ or $77.0 \mathrm{ppm}$ for ${ }^{13} \mathrm{C}$ in case of $\mathrm{CDCl}_{3}$ as solvent) as references.

\subsection{Mushroom Material}

Sporocarps of T. atrotomentosa $(2 \mathrm{~kg})$ were collected in the vicinity of Szeged (Hungary) in August-October 2015. Fruiting bodies of T. atrotomentosa were stored at $-20{ }^{\circ} \mathrm{C}$ until processing. A voucher specimen (No. P7) has been deposited at the Department of Pharmacognosy, University of Szeged, Hungary.

\subsection{Extraction and Isolation}

The fruiting bodies of $T$. atrotomentosa $(2 \mathrm{~kg})$ were extracted with methanol $(11.5 \mathrm{~L})$. After concentration, the dry methanol extract $(90.0 \mathrm{~g})$ was dissolved in $50 \%$ aqueous $\mathrm{MeOH}(600 \mathrm{~mL})$ and solvent-solvent partition was performed with $n$-hexane and chloroform $(5 \times 500 \mathrm{~mL}$ each) yielding $n$-hexane, chloroform and aqueous $\mathrm{MeOH}$-soluble phases. The chloroform-soluble phase was evaporated and the residue (8.56 g) was roughly separated with flash column chromatography on silica gel column using gradient system of $n$-hexane-acetone. The obtained fractions were combined based on TLC checking resulting in seven fractions (I-VII). Fraction II ( $882.5 \mathrm{mg})$ eluted with $n$-hexane-acetone 85:15, was further separated by multiple flash chromatography with increasing polarity of $n$-hexane-acetone. Two of the resulted fractions were finally purified with normal-phase HPLC using cyclohexane-isopropanol-water isocratic eluent system to result in compounds $\mathbf{1}(21.2 \mathrm{mg})$ and $2(14.0 \mathrm{mg})$. Fraction IV (1.3 g) was subjected to flash column chromatography using $n$-hexane-acetone gradient system as mobile phase, and resulted in eight fractions (IV/1-8). The purification of IV/5 (63.4 $\mathrm{mg}$ ) was performed by HPLC using mobile phase of cyclohexane-isopropanol-water 78:22:0.1 and led to the isolation of $3(15.8 \mathrm{mg})$. Finally, fraction IV/6 (38.3 mg) was analyzed with HPLC applying an isocratic mobile phase of cyclohexane-isopropanol-water 75:25:0.1 yielding 4 (1.3 mg).

\subsection{Determination of MIC Values}

The in vitro antibacterial activities were assayed using microdilution method based on the guideline of Clinical and Laboratory Standards Institute against bacterial strains [20] including Escherichia coli (SZMC 6271), Pseudomonas aeruginosa (SZMC 2329), Staphylococcus epidermidis (SZMC 14531) Staphylococcus aureus (SZMC 14611), Bacillus subtilis (SZMC 0209), Acinetobacter baumanii (SZMC 24075), Escherichia coli ESBL (SZMC 24090), Moraxella catarrhalis (ATCC 25238). The suspensions of each bacteria were prepared from overnight broth cultures cultivated in Luria-Bertani broth (LB, $10 \mathrm{~g} / \mathrm{L}$ tryptone, $10 \mathrm{~g} / \mathrm{L}$ sodium chloride, $5 \mathrm{~g} / \mathrm{L}$ yeast extract) at $37^{\circ} \mathrm{C}$ and the concentrations of suspensions were adjusted to $10^{5}$ cells $/ \mathrm{mL}$. The DMSO solution of the investigated compounds as well as the reference agents were diluted with the LB media in the final concentration ranging from $1000 \mu \mathrm{g} / \mathrm{mL}$ to $6.25 \mu \mathrm{g} / \mathrm{mL}$. The 96-well plates were prepared by dispensing into each well $100 \mu \mathrm{L}$ of LB containing the bacterial cells and $100 \mu \mathrm{L}$ of dissolved compounds and incubated for $24 \mathrm{~h}$ at $37^{\circ} \mathrm{C}$. The mixture of $100 \mu \mathrm{L}$ LB broth and $100 \mu \mathrm{L}$ sample solvent were used as blank sample for the background correction, while $100 \mu \mathrm{L}$ of bacterial cultures with $100 \mu \mathrm{L}$ solvents without the compounds was applied as positive control, while standard antibiotics were used as reference agents. Absorbance was measured at $620 \mathrm{~nm}$ 
after $24 \mathrm{~h}$ with microplate reader (SPECTROstar Nano, BMG Labtech, Ortenberg, Germany) and the MIC values were determined as the lowest concentration where the inhibition was higher than $10 \%$ of the positive control after the blank correction.

\subsection{Investigation of Synergistic Effect Between Cefuroxime and the Isolated Ccompounds}

Cefuroxime was used in checkerboard assay [21] in combination with the isolated compounds against MRSA (SZMC 6270). The suspensions of the bacteria were prepared from overnight broth cultures cultivated in LB broth at $37^{\circ} \mathrm{C}$ and the concentrations of suspensions were adjusted to $10^{5}$ cells $/ \mathrm{mL}$. Into each well of the 96 -well plates, $100 \mu \mathrm{L}$ of LB broth were added containing the bacterial cells, which was completed with $50 \mu \mathrm{L}$ of each compound and $50 \mu \mathrm{L}$ of cefuroxime. Double dilutions of both the antibiotic and test compounds were carried out in five levels started from their related MIC values (isolated compounds: $250 \mu \mathrm{g} / \mathrm{mL}-15.6 \mu \mathrm{g} / \mathrm{mL}$; cefuroxime: $300 \mu \mathrm{g} / \mathrm{mL}-18.75 \mu \mathrm{g} / \mathrm{mL}$ ). The mixture of $100 \mu \mathrm{L}$ LB broth and $100 \mu \mathrm{L}$ sample solvents were used as blank sample for the background correction, while $100 \mu \mathrm{L}$ of bacterial cultures with $100 \mu \mathrm{L}$ solvents without the compounds and antibiotic was applied as positive control. The plates were incubated for $24 \mathrm{~h}$ at $37{ }^{\circ} \mathrm{C}$ and the absorbance of the wells were measured at $600 \mathrm{~nm}$ with microplate reader (SPECTROstar Nano) to observe for growth of the test organism, which was expressed in percentages of the positive control. The $\sum$ FICIs were calculated as follows: $\sum$ FICI = FIC A + FIC B, where FIC A is the MIC of drug A (cefuroxime) in the combination/MIC of drug A (cefuroxime) alone, and FIC B is the MIC of drug B (isolated compounds) in the combination/MIC of drug B (isolated compounds) alone. The combination is considered synergistic when the $\sum$ FIC is $\leq 0.5$, indifferent when the $\sum$ FIC is $>0.5$ to $<2$, and antagonistic when the $\sum F I C$ is $\geq 2$.

\subsection{Investigation of Antioxidant Activity}

\subsubsection{DPPH Method}

The analysis of free radical scavenging activity was carried out by the modified method of Miser-Salihoglu et al. [22]. The DPPH (2,2'-diphenyl-1-picrylhydrazyl) method was performed on a 96-well microplate. Microdilution series of extracts and the isolated compounds (concentration of $1 \mathrm{mg} / \mathrm{mL}$ dissolved in DMSO), were made starting from $150 \mu \mathrm{L}$. To each well $50 \mu \mathrm{L}$ of DPPH solution $(100 \mu \mathrm{M})$ was added. The absorbance was measured after $30 \mathrm{~min}$ at $550 \mathrm{~nm}$ with a FLUOstar Optima BMG Labtech plate-reader. The less active samples were measured again in $2 \mathrm{mg} / \mathrm{mL}$ concentration. Subsequent dilution series were made using the most effective samples, starting from $100 \mu \mathrm{L}$, to precisely evaluate half maximal effective concentration (EC 50 values). As standard, ascorbic acid was used. DPPH and ascorbic acid standard were purchased from Sigma-Aldrich Hungary. EC $\mathrm{E}_{50}$ $(\mathrm{mg} / \mathrm{mL})$ values were calculated using GraphPad Prism 6.0 software (GraphPad Software, La Jolla, CA, USA).

\subsubsection{ORAC Assay}

The ORAC assay was carried out on a 96-well microplate according to the method of Mielnik et al. [23]. $20 \mu \mathrm{L}$ of extracts or pure compounds of $0.01 \mathrm{mg} / \mathrm{mL}$ concentration were mixed with $60 \mu \mathrm{L}$ of AAPH ((2,2'-azobis(2-methyl-propionamidine)dihydrochloride) (12 mM final concentration) and $120 \mu \mathrm{L}$ of fluorescein solution (70 nM final concentrations), then the fluorescence was measured through $3 \mathrm{~h}$ with $1.5 \mathrm{~min}$ cycle intervals with FLUOStar Optima BMG Labtech plate-reader. All the experiments were carried out in triplicate, Trolox was used as standard. AAPH free radical and Trolox standard ((土)-6-hydroxy-2,5,7,8-tetramethyl-chromane-2-carboxylic acid) were purchased from Sigma-Aldrich Hungary. Fluorescein was purchased from Fluka Analytical (Tokyo, Japan). The antioxidant capacity was expressed as mmol Trolox equivalent per $\mathrm{g}$ of dry extract ( $\mathrm{mmol} \mathrm{TEg}^{-1}$ ), with help of GraphPad Prism 6.0 (GraphPad Software, La Jolla, CA, USA). 
Supplementary Materials: Supplementary materials are available online.

Author Contributions: Z.B. and M.D. performed the spectral analysis and structure determination; B.K. performed the extraction and isolation; A.Sz. and B.Cs-L. conceived and designed the microbiological experiments, E.K. performed the antibacterial assay; Z.P.Z. performed the antioxidant assays; E.U. contributed reagents and analysis tools; J.H. and A.V. conceived and designed the experiments; B.K. and A.V. wrote the paper. All authors reviewed the manuscript.

Funding: This research received no external funding.

Acknowledgments: This work was partly supported by the GINOP research program (project no. 2.3.2-15-2016-00012) funded by the European Regional Development Fund. Financial support from the Hungarian National Research, Development and Innovation Fund (PD 124476) is gratefully acknowledged.

Conflicts of Interest: The authors declare no conflict of interest. The founding sponsors had no role in the design of the study; in the collection, analyses, or interpretation of data; in the writing of the manuscript, and in the decision to publish the results.

\section{References}

1. Wasser, S.P. Medicinal mushroom science: history, current status, future trends and unsolved problems. Int. J. Med. Mushrooms 2010, 12, 1-16. [CrossRef]

2. Liktor-Busa, E.; Kovács, B.; Urbán, E.; Hohmann, J.; Ványolós, A. Investigation of Hungarian mushrooms for antibacterial activity and synergistic effects with standard antibiotics against resistant bacterial strains. Lett. Appl. Microbiol. 2016, 62, 437-443. [CrossRef] [PubMed]

3. Gaylord, M.C.; Benedict, R.G.; Hatfield, G.M.; Brady, L.R. Isolation of diphenyl-substituted tetronic acids from cultures of Paxillus atrotomentosus. J. Pharm. Sci. 1970, 59, 1420-1423. [PubMed]

4. Besl, H.; Bresinsky, A.; Geigenmüller, G.; Herrmann, R.; Kilpert, C.; Steglich, W. Flavomentine und Spiromentine, neue Terphenylchinon-Derivate aus Paxillus atrotomentosus und P. panuoides (Boletales). Liebigs Ann. Chem. 1989, 8, 803-810. [CrossRef]

5. Gaylord, M.C.; Brady, L.R. Comparison of Pigments in Carpophores and Saprophytic Cultures of Paxillus panuoides and Paxillus atrotomentosus. J. Pharm. Sci. 1971, 60, 1503-1508. [CrossRef] [PubMed]

6. Holzapfel, M.; Kilpert, C.; Steglich, W. Über Leucomentine, farblose Vorstufen des Atromentins aus dem Samtfußkrempling (Paxillus atrotomentosus). Liebigs Ann. Chem. 1989, 8, 797-801. [CrossRef]

7. Buchanan, M.S.; Hashimoto, T.; Takaoka, S.; Asakawa, Y. (+)-Osmundalactone, $\gamma$-lactones and spiromentins from the fungus Paxillus atrotomentosus. Phytochemistry 1995, 40, 1251-1257. [CrossRef]

8. Hashimoto, T.; Arakawa, T.; Tanaka, M.; Asakawa, Y. A Novel Dimeric Lactone Bis-osmundalactone from the Japanese Inedible Mushroom Paxillus atromentosus var. bambusinus. Heterocycles 2002, 56, 581-588.

9. Vokáč, K.; Buděšínský, M.; Harmatha, J.; Ṕ́šs, J. New ergostane type ecdysteroids from fungi. Ecdysteroid constituents of mushroom Paxillus atrotomentosus. Tetrahedron 1998, 54, 1657-1666.

10. Beattie, K.D.; Rouf, R.; Gander, L.; May, T.W.; Ratkowsky, D.; Donner, C.D.; Gill, M.; Grice, I.D.; Tiralongo, E. Antibacterial metabolites from Australian macrofungi from the genus Cortinarius. Phytochemistry 2010, 71 , 948-955. [CrossRef] [PubMed]

11. Ishikawa, N.K.; Fukushi, Y.; Yamaji, K.; Tahara, S.; Takahashi, K. Antimicrobial cuparene-type sesquiterpenes, enokipodins C and D, from a mycelial culture of Flammulina velutipes. J. Nat. Prod. 2001, 64, 932-934. [CrossRef] [PubMed]

12. Liu, X.T.; Winkler, A.L.; Schwan, W.R.; Volk, T.J.; Rott, M.A.; Monte, A. Antibacterial compounds from mushrooms I: a lanostane-type triterpene and prenylphenol derivates from Jahnoporus hiritus and Albatrellus flettii and their activities against Bacillus cereus and Enterococcus faecalis. Planta Med. 2010, 76, 182-185. [CrossRef] [PubMed]

13. Hollenbeak, K.H.; Kuehne, M.E. The isolation and structure determination of the fern glycoside osmundalin and the synthesis of its aglycone osmundalactone. Tetrahedron 1974, 30, 2307-2316. [CrossRef]

14. Numata, A.; Hokimoto, K.; Takemura, T.; Katsuno, T.; Yamamoto, K. Plant Constituents Biologically Active to Insects. V. Antifeedants for the Larvae of the Yellow Butterfly, Eurema hecabe mandarina, in Osmunda japonica. (1). Chem. Pharm. Bull. 1984, 32, 2815-2820. [CrossRef]

15. Calì, V.; Spatafora, C.; Tringali, C. Polyhydroxy- $p$-terphenyls and related $p$-terphenylquinones from fungi: Overview and biological properties. Stud. Nat. Prod. Chem. 2003, 29, 263-307. 
16. Belsare, M.H.; Bapat, G.S.; Ranadive, K.R.; Vaidya, J.G.; Deokule, S.S. In vitro susceptibility testing of some Phellinus species against Acinetobacter baumannii from Maharashtra India. J. Med. Plants Res. 2010, 4, 1335-1338.

17. Schwan, W.R.; Dunek, C.; Gebhardt, M.; Engelbrecht, K.; Klett, T.; Monte, A.; Toce, J.; Rott, M.; Volk, T.J.; LiPuma, J.J.; et al. Screening a mushroom extract library for activity against Acinetobacter baumannii and Burkholderia cepacia and the identification of a compound with anti-Burkholderia activity. Ann. Clin. Microbiol. Antimicrob. 2010, 9, 4. [CrossRef] [PubMed]

18. Benedict, R.G.; Brady, L.R. Antimicrobial Activity of Mushroom Metabolites. J. Pharm. Sci. 1972, 61, 1820-1822. [CrossRef]

19. Brewer, D.; Jen, W.C.; Jones, G.A.; Taylor, A. The antibacterial activity of some naturally occurring 2,5-dihydroxy-1,4-benzoquinones. Can. J. Microbiol. 1984, 30, 1068-1072.

20. Clinical and Laboratory Standards Institute (CLSI). Methods for Dilution Antimicrobial Susceptibility Tests for Bacteria That Grow Aerobically: Approved Standard; Clinical and Laboratory Standards Institute: Wayne, PA, USA, 2015.

21. Orhan, G.; Bayram, A.; Zer, Y.; Balci, I. Synergy Tests by E Test and Checkerboard Methods of Antimicrobial Combinations against Brucella melitensis. J. Clin. Microbiol. 2005, 43, 140-143. [CrossRef] [PubMed]

22. Miser-Salihoglu, E.; Akaydin, G.; Caliskan-Can, E.; Yardim-Akaydin, S. Evalution of antioxidant activity of various herbal folk medicines. J. Nutr. Food Sci. 2013, 3, 222.

23. Mielnik, M.B.; Rzeszutek, A.; Triumf, E.C.; Egelandsdal, B. Antioxidant and other quality properties of reindeer muscle from two different Norwegian regions. Meat Sci. 2011, 89, 526-532. [CrossRef] [PubMed]

Sample Availability: Samples of the compounds 1-2 are available from the authors.

(C) 2018 by the authors. Licensee MDPI, Basel, Switzerland. This article is an open access article distributed under the terms and conditions of the Creative Commons Attribution (CC BY) license (http:/ / creativecommons.org/licenses/by/4.0/). 